\title{
Currículo, gênero e sexualidade: uma análise sobre as práticas discursivas e não-discursivas que reforçam posições de gênero e sexualidade na escola
}

\author{
Currículo, género y sexualidad: un análisis sobre las prácticas discursivas \\ y no discursivas que refuerzan posiciones de género y sexualidad en las \\ escuelas
}

Curriculum, gender and sexuality: an analysis of discursive and non-
discursive practices that reinforcegender and sexuality positions in school

Juliane dos Santos Porto ${ }^{1}$

\begin{abstract}
Resumo
Entendendo que discursos neoconservadores proliferam na educação brasileira, no atual contexto, e reforçam posições binárias e heteronormativas de gênero e sexualidade nas escolas, o propósito desse estudo teórico é problematizar essas práticas discursivas e não-discursivas em expansão. Afinal a escola é um dos espaços onde se estabelece o que é o masculino e o feminino por meio de processos de rotulação e segregação. Os currículos incidem sobre a produção de subjetividades e podem naturalizar posições de gênero e sexualidade. A questão que se coloca é desnaturalizar essas verdades tratadas como absolutas. Intensificar discursos em defesa de currículos e práticas pedagógicas que abordem diferenças de gênero e sexualidades nas escolas. Pois, há outras práticas discursivas e não-discursivas que disputam legitimidade e que funcionam como linhas de fuga ao padrão estabelecido. Essas forças não deixam de habitar, circular e resistir no interior das escolas.
\end{abstract}

Palavras-Chave: Currículo; Escola; Gênero; Sexualidade.

\section{Resumen}

En el sentido de que los discursos neoconservadores proliferan en la educación brasileña, en el actual contexto, y refuerzan posiciones binarias y heteronormativas de género y sexualidad en las escuelas, el propósito de este estudio teórico es problematizar esas prácticas discursivas y no discursivas en expansión. Al final la escuela es uno de los espacios donde se establece lo que es lo masculino y lo femenino por medio de procesos de rotulación y segregación. Los currículos se centran en la producción de subjetividades y pueden naturalizar posiciones de género y sexualidad. La cuestión que se plantea es desnaturalizar esas verdades tratadas como absolutas. Intensificar discursos en defensa de currículos y prácticas pedagógicas que aborden diferencias de género y sexualidades en las escuelas. Pues, hay otras prácticas discursivas y no discursivas que disputan legitimidad y que funcionan como líneas de fuga al padrón establecido. Estas fuerzas no dejan de habitar, circular y resistir en el interior de las escuelas.

Palabras clave: Currículo; escuela; género; sexualidad.

\begin{abstract}
Understanding that speeches neoconservatives proliferate in Brazilian education, in the current context, and reinforce binary and heteronormativas positions of gender and sexuality in schools, the purpose of this study is to

\footnotetext{
${ }^{1}$ Graduada em Letras - Português e suas respectivas literaturas; Universidade Federal do Pampa; discente do Programa de Mestrado Acadêmico em Ensino; Universidade Federal do Pampa; Bagé, Rio Grande do Sul, Brasil; juporto9000@hotmail.com
} 
problematize these discursive practices and non-discursive in expansion. After all, the school is one of the space where establishes what is the masculine and the feminine through processes of segregation and labeling. The curriculums focus on the production of subjectivities and can naturalize positions of gender and sexuality. The question is to denaturalize these truths treated as absolute. Intensify speeches in defense of curricula and pedagogical practices that address gender differences and sexualities in schools. Because there are other discursive practices and non-discursive that compete for legitimacy and that work as lines of escape to the established standard. These forces do not cease to dwell, circular and resist inside of schools.

Keywords: Curriculum; School; Genre; Sexuality

\section{Introdução}

O presente artigo busca problematizar a circulação de discursos neoconservadores no âmbito educacional brasileiro, percebendo-se que tais demandas estão presentes nas políticas educacionais em curso e nos contextos escolares, entre outras formas, pela ação do movimento "Escola sem Partido" que advoga contra a abordagem das diferenças de gênero e sexualidade nos currículos, afirmando atuar em defesa da família formada por relações heteroafetivas.

A linha de análise desta problemática se fundamente numa perspectiva foucaultiana, no sentido de entender como práticas discursivas e não-discursivas reforçam posições binárias e heteronormativas de gênero e sexualidade nos ambientes escolares. Para Foucault (apud FISHER, 2001, p. 198), os discursos produzem verdades, materialidades:

[...] em toda sociedade a produção do discurso é ao mesmo tempo controlada, selecionada, organizada e redistribuída por certo número de procedimentos que têm por função conjurar seus poderes e perigos, dominar seu acontecimento aleatório, esquivar sua pesada e temível materialidade (FOUCAULT, 1996, p. 10).

As práticas discursivas são atravessadas por práticas não-discursivas, ou seja, relações de poder e saber que exercem controle sobre o que pode ou não ser dito. Historicamente, a circulação de discursos em torno da sexualidade que escapa ao padrão heteronormativo é interditada em nome da preservação das instituições e de valores morais. Não se pode dizer qualquer coisa em qualquer lugar (FOUCAULT, 1996).

Assim, de acordo com Butler (1990, apud SALIH, 2015, p. 87) “a percepção e o corpo são discursivamente construídos através da exclusão, do tabu e da abjeção". Posições binárias e relações heteronormativas são reforçadas pelos discursos neoconservadores e pelas práticas não-discursivas constituídas por relações de poder e saber, regimes de verdade e processos de subjetivação que incidem sobre a produção dos corpos.

Por mais que o discurso seja aparentemente bem pouca coisa, as interdições que o atingem revelam logo, rapidamente, sua ligação com o desejo e como poder. Nisto não há nada de espantoso, visto que o discurso - como a psicanálise nos mostrou não é simplesmente aquilo que manifesta (ou oculta) o desejo; é, também, aquilo que é o objeto do desejo; e visto que - isto a história não cessa de nos ensinar - o 
discurso não é simplesmente aquilo que traduz as lutas ou os sistemas de dominação, mas aquilo por que, pelo que se luta, o poder do qual nos queremos apoderar (FOUCAULT, 1996, p 10).

Contudo, outros discursos também estão em disputa. Discursos que sinalizam linhas de fuga (DELEUZE; GUATTARI, 2011) ao subverter a ordem instituída, desmontando verdades e normas, instigando a aprofundar o debate e perceber a complexidade das práticas discursivas e não-discursivas em relação à produção de gêneros e sexualidades.

\section{Os discursos neoconservadores do movimento "Escola sem Partido"}

Discursos neoconservadores têm proliferado em escala global nas sociedades ocidentais. Em linhas gerais, o neoconservadorismo pode ser definido como exaltação ao passado, uma tentativa de voltar aos costumes antigos, um ideal moralista. Para os neoconservadores a sociedade deve respeitar a "ordem natural" (APPLE, 2004, p. 51).

Ordem essa em que gênero e sexualidade são atribuídos biologicamente, existindo apenas o padrão binário e heteronormativo: homem/mulher. Neoconservadores negam toda e qualquer existência ou relação que fuja a esse padrão. Também, contrários a miscigenação de culturas e povos, acreditam na superioridade de um “deus" único e apresentam um forte ideal patriota, nacionalista.

No campo educacional, os discursos neoconservadores foram reforçados com a atuação do movimento "Escola sem partido", criado em 2004, pelo advogado Miguel Nagib em virtude, segundo ele, de uma situação em que um professor de história de sua filha havia comparado Che Guevara a São Francisco de Assis, o que considerou absurdo. Sobre isso Nagib disse: "As pessoas que querem fazer a cabeça das crianças associam as duas coisas e acabam dizendo que Che Guevara é um santo" (EL PAÍS BRASIL, 2016).

Ao veicular tal notícia, o EL PAÍS justificou a intenção do professor como uma analogia ao fato de que Che e São Francisco eram exemplos de pessoas que abriram mão dos interesses pessoais em nome de uma causa social. Não contente com a atitude do professor, Nagib decidiu escrever uma carta aberta e distribuir trezentas cópias no estacionamento da escola de sua filha. O site relata o fracasso da ação, Nagib foi chamado na escola e, além de não ter recebido apoio dos pais, os alunos fizeram manifestações a favor do professor. Descontente com os fatos, Nagib decidiu criar o movimento "Escola Sem Partido", uma entidade que coloca em circulação discursos contra os supostos "abusos de professores doutrinadores", sobre os jovens. O movimento visa acabar com a chamada "doutrinação marxista de professores da rede pública de ensino". Para seu idealizador e seus seguidores, além da proibição do professor manifestar posições ideológicas sobre temas como política e 
religião, a escola não é espaço para assuntos como gênero e sexualidade. Segundo ele, o professor se vale de seu carisma e autoridade em sala de aula para doutrinar as crianças. Nagib também diz que o movimento não pode ser acusado de censura, pois: "Não é cerceamento à liberdade de expressão porque o professor não tem direito à liberdade de expressão na sala de aula” (EL PAÍS BRASIL, 2016).

Discursos neoconservadores como esse do "Escola sem Partido" que circulam na educação, estão associados ao neoliberalismo. Nesse sistema, que segue um padrão já colocado em prática em países como os Estados Unidos, a educação deve se curvar aos apelos econômicos, ou seja, cabe à escola priorizar a formação de capital humano adequado às exigências do mercado de trabalho competitivo e flexível. Assim, os currículos escolares devem centrar no ensino de habilidades e competências que são requisitadas aos trabalhadores para que estejam aptos a disputarem as vagas de emprego.

Desse modo, o ensino de algumas áreas como linguagem e matemática é valorizado, enquanto outras áreas como sociologia, filosofia, história e artes são depreciadas. Para os neoliberais e neoconservadores não cabe nos currículos o estudo e o debate das diferenças sociais, culturais, étnico-raciais, sexuais. E toda essa movimentação se faz pelo claro "medo do outro", como diz Apple (2004, p. 52):

Por trás de grande parte disso, está uma clara sensação de perda - uma perda de fé, de comunidades imaginadas, de uma visão quase pastoral de pessoas semelhantes que compartilhem de normas e valores, e nas quais "a tradição ocidental" reine suprema. Isso se assemelha bastante à discussão de Mary Douglas da pureza e do perigo, em que aquilo que se imaginava existir é sagrado, e a "poluição" é temida acima de tudo. Oposições binárias do tipo nós/eles dominam esse discurso, e devemos temer a cultura do "outro".

O medo ao diferente, a repulsa aos pensamentos de esquerda, o fundamentalismo religioso muito forte e o profundo sentimento de necessidade de poder são peças chave para que esses movimentos passem a intervir na educação.

Desse modo, tabus e preconceitos que herdamos historicamente são reforçados diante do medo e da falta de abertura para dialogar sobre sexualidade.

[...] embora presente em todos os dispositivos de escolarização, a preocupação com a sexualidade geralmente não é apresentada de forma aberta. Indagados/as sobre essa questão, é possível que dirigentes ou professores/as façam afirmações do tipo: "em nossa escola nós não precisamos nos preocupar com isso, nós não temos nenhum problema nessa área", ou então, "nós acreditamos que cabe à família tratar desses assuntos".

É preciso pensar como se constiuem os discurso neoconservadores: de que família fala o movimento "Escola sem Partido"? Ao enunciado família atribui-se um único sentido: família branca, constituída por um pai; homem, hétero, cis, uma mãe; mulher, também hétero, 
cis; possuidores de um padrão de vida de classe média/alta em que o pai trabalha fora e a mãe cuida da casa. Nessa configuração familiar a mãe, que é a que fica mais tempo com os filhos, decide se tratará sobre o tema com eles ou não. Mas, quantas famílias brasileiras se enquadram nesse padrão?

É importante problematizar o próprio conceito de família, afinal vivemos em um país onde, segundo dados do Conselho Nacional de Justiça (CNJ), com base no Censo Escolar de 2011, 5,5 milhões de crianças não tinham registrado o nome do pai em suas certidões de nascimento (EXAME, 2013).

Segundo o Instituto Brasileiro de Geografia e Estatística (IBGE) entre 2005 e 2015 o aumento foi de 1,1 milhão de famílias compostas por mães solteiras. Também cabe pensar nos casos de crianças criadas pelos avós, adotados por casais do mesmo sexo, entre tantos outros. Tais dados mostram a precariedade do argumento do "Escola sem Partido" que defende a educação sexual como papel apenas da família.

Outra problemática desse discurso que atribui à família a responsabilidade de tratar sobre gêneros e sexualidades é o fato de que, segundo dados do Ministério da Saúde, coletados entre 2011 e 2017 e publicados no Portal de Notícias G1, em 2018, a maioria dos casos de violência sexual contra crianças e adolescentes acontece dentro de casa.

Discursos de exclusão, de competição, sob um olhar binário, cis, heteronormativo e machista tem o papel de definir quais identidades de gênero e sexualidades são aceitas e respeitadas em sociedade, além de tentar firmá-las. Antes mesmo de virmos ao mundo, ao saberem o nosso "sexo", o sexo definido e imposto por características físicas, os pais já moldam nossa identidade fazendo ligação com essa característica. Há uma necessidade de saber o sexo do bebê, todo movimento de recepção dessa criança vai ser norteado por essa informação. Não só os pais, mas as pessoas que rodeiam a pessoa grávida e o bebê exigem uma definição de sexo. Somos diariamente interpelados por discursos que normatizam gêneros e sexualidades. Meninas ganham bonecas e meninos carrinhos e se um menino brincar de boneca pode sofrer todo tipo de castigo e repressão.

Outra questão importante é pensar no quanto os discursos religiosos se instauram em uma sociedade que por lei é laica. A proibição de assuntos como sexualidade, na escola, é impulsionada por um discurso religioso que, por estar alinhado ao neoconservadorismo acredita em uma sociedade pura, livre de diversidade e que prega a demonização do diferente.

Todo discurso regido pelo neoconservadorismo expressa uma repulsa ao "outro", ao desconhecido, ao diferente, e essa ideia de "outro" exclui, separa os "bons" dos "maus", "nós" e "eles". Nessa oposição binária, Tomaz Tadeu da Silva (2014, p. 83) citando o filósofo 
francês Jaques Derrida, nos diz que: “oposições binárias não expressam uma simples divisão do mundo em duas classes simétricas: em uma oposição binária um dos termos é sempre privilegiado", ou seja, as relações de poder, aí, se mostram claras. Se temos um padrão social, regido pela heteronormatividade, tudo que está fora dessa ordem é demonizado. Ainda para Tomaz Tadeu (2014, p. 83) "questionar identidade e diferença como relações de poder significa problematizar os binarismos em torno dos quais elas se organizam".

Mas será que os discursos neoconservadores encontram ressonância nas escolas? Tradicionalmente, a escola tem produzido processos de exclusão em seus currículos. Assim diz Louro (1997, p. 57):

Diferenças, distinções, desigualdades... A escola entende disso. Na verdade, a escola produz isso. Desde seus inícios, a instituição escolar exerceu uma ação distintiva. Ela se incumbiu de separar os sujeitos - tornando aqueles que nela entravam distintos dos outros, os que a ela não tinham acesso. Ela dividiu também, internamente, os que lá estavam, através de múltiplos mecanismos de classificação, ordenamento, hierarquização. A escola que nos foi legada pela sociedade ocidental moderna começou por separar adultos de crianças, católicos de protestantes. Ela também se fez diferente para os ricos e para os pobres e ela imediatamente separou os meninos das meninas.

Os discursos neoconservadores estão ganhando força nas políticas educacionais no Brasil, setores que representam esses discursos estão em ascensão, sejam eles grupos religiosos, políticos, econômicos, culturais. E quanto mais esses discursos ganham força, e esses grupos se reconhecem neles, se fortalecem políticas educacionais que governam os currículos e reforçam o controle do trabalho docente.

Essa verdade se dá pelo momento histórico em que estamos inseridos, mas é preciso perceber que enquanto o discurso neoconservador ganha mais força, movimentos com discursos contrários também disputam esses espaços de verdade.

\section{A contracorrente ao neoconservadorismo: movimentos feministas}

O neoconservadorismo representa uma reação aos movimentos que defendem a liberdade de gênero e sexualidade e os direitos dos grupos e sujeitos à margem do padrão social instituído. Há um número significativo de artistas que se expressam como dragqueens, transexuais, gays; no cinema, teatro e dramaturgia, mesmo que timidamente, são postos em suas histórias personagens com diversas identidades de gênero e sexualidades, vivendo papéis cada vez menos estereotipados. Essas forças de resistência não surgiram recentemente, desde muito tempo há uma urgência de esses discursos resistirem e existirem, e o movimento feminista é exemplo disso. 
O feminismo ganhou força na virada do século com o "sufragismo", movimento que reivindicava o direito das mulheres ao voto. Ao adquirir uma relevante visibilidade e força, foi reconhecido como a "primeira onda" feminista. Vale ressaltar que essa primeira movimentação estava ligada apenas às mulheres brancas e de classe média, suas reivindicações visavam apenas esse público, esse grupo não se mobilizada sobre outras pautas. Com isso "foi seguido de uma certa acomodação do movimento" (LOURO, 1997, p. $15)$.

Ao final da década de 1960, na "segunda onda", o feminismo começa a se preocupar também com as teorizações sobre o conceito de gênero. O ano de 1968 representa um "marco da rebeldia e da contestação". "A referência é útil para assinalar, de uma forma muito concreta, a manifestação coletiva da insatisfação e do protesto que já vinham sendo gestados há algum tempo" (LOURO, 1997, p. 15).

França, Estados Unidos, Alemanha e Inglaterra tiveram os movimentos atuantes e fortes, unindo negros, mulheres, jovens e estudantes inconformados com "os tradicionais arranjos sociais e políticos, às grandes teorias universais, ao vazio formalismo acadêmico, à discriminação, à segregação e ao silenciamento". É nesse contexto que o movimento feminista contemporâneo ressurge "expressando-se não apenas através de grupos de conscientização, marchas e protestos públicos, mas também através de livros, jornais e revistas" (LOURO, 1997, p. 15).

Pode-se observar que a primeira e a segunda onda estão diretamente ligadas ao seu momento histórico. Em um primeiro momento, enquanto as reivindicações priorizavam a inserção na vida pública, a chamada "segunda onda" abrange um número maior de sujeitos e também aborda aspectos políticos além dos econômicos. Dividir esses momentos em blocos, ondas, é apenas uma forma de facilitar a compreensão, afinal todos esses momentos são atravessados por outros acontecimentos, fazem outras relações, são construídos gradativamente.

E assim, nas universidades e escolas, o contingente de movimentos, militantes e pesquisadoras que tratam da temática feminino(s) e feminismo(s) e seus desdobramentos em suas produções científicas vêm crescendo cada vez mais.

Entre os estudos contemporâneos cabe ressaltar a Teoria Queer, pensada e disseminada por Judith Butler, professora de retórica e literatura comparada na Universidade da Califórnia, em Berkeley. Em seu livro Problemas de Gênero: feminismo e subversão (2016), ela questiona a dicotomia sexo/gênero, a heterossexualidade compulsória, e afirma que sexo, gênero e sexualidades são construídos historicamente por discursos, levando em 
consideração relações de poder e submissão em uma sociedade patriarcal regida pela heterossexualidade e binarismos.

É então por essa ótica que se problematiza aqui os currículos, pensando, por exemplo, quantas escritoras mulheres são lidas na Literatura e na Língua Portuguesa? Quantas cientistas são estudadas nas aulas de Biologia, Química, Física? A resposta mais provável é poucas ou nenhuma. Observa-se, então, que: "O currículo é, entre outras coisas, um artefato de gênero: um artefato que, ao mesmo tempo, corporifica e produz relações de gênero" (SILVA, T, T.2007, p. 97).

Butler (2010, p. 236) expressa a complexidade dos conceitos gênero e sexualidades ao dizer que:

Se a verdade interna do gênero é uma fabricação, e se o gênero verdadeiro é uma fantasia instituída e inscrita sobre a superfície dos corpos, então parece que os gêneros não podem ser nem verdadeiros nem falsos, mas somente produzidos como efeitos de verdade de um discurso sobre a identidade primária e estável.

Ou seja, não é mais possível acreditar que haja uma identidade fixa, certa, inata, onde meninas vestem rosa, meninos vestem azul. Frente as novas identidades não se busca uma mera aceitação do diferente, colocá-lo em posição de destaque, de rotulação. Professores, comunidades escolares, universidades, famílias, precisam colocar em suspenso essas verdades sobre os considerados diferentes e entender que sexualidade e gênero, são conceitos mais complexos. Então, trazer esses temas para o debate sobre currículo é de suma importância para entender que verdades podem ser desnaturalizadas.

\section{Pensar rizomaticamente os currículos}

Ao finalizar este texto, reafirma-se a urgência em resistir aos discursos neoconservadores, e mais do que isso, entender que gêneros e sexualidades são enunciados construídos discursivamente e que práticas não-discursivas também fazem parte desse processo, ou seja, condições históricas, sociais, políticas e econômicas corroboram para a proliferação de diferentes discursos que disputam legitimidade.

Perceber a escola como solo fértil para o debate em torno das diferenças de gênero e sexualidades possibilita pensar os currículos como produções rizomáticas onde as aprendizagens aconteçam em múltiplas conexões e o conhecimento não esteja centrado em algo, mas construído por meio de atravessamentos e relações, uma vez que "qualquer ponto de um rizoma pode ser conectado a qualquer outro e deve sê-lo. É muito diferente da árvore ou da raiz que fixam um ponto, uma ordem” (DELEUZE; GUATTARI, 2001, p. 22). 
Pensar em linhas de fuga, não como um caminho único, uma saída, mas em linhas múltiplas que escapam de tentativas totalizadoras, movimentos que subvertem qualquer ordem estabelecida. Assim, "a linha de fuga marca, ao mesmo tempo: a realidade de um número de dimensões finitas que a multiplicidade preenche efetivamente; a impossibilidade de toda dimensão suplementar sem que a multiplicidade se transforme segundo esta linha [...]” (DELEUZE; GUATTARI, 2001, p. 25)

Os currículos podem ser formas de reforçar verdades neoconservadoras, mas também podem intensificar o debate, multiplicar o pensamento, produzir dissidências pautadas em estudos culturais e feministas, gays e lésbicos, filosofia da diferença e pedagogias da diversidade, constituindo um pós-currículo. Essa configuração de currículo não trata o aluno como mero número, mão de obra a serviço das empresas, e, contrariando as práticas discursivas neoliberais, acredita em "uma educação pública, gratuita e de qualidade" para todos e todas (LOPES; MACEDO, 2002, p. 104).

Para isso, segundo Louro (1997, p. 86) não podemos "alimentar uma postura reducionista ou ingênua - que supõe ser possível transformar toda a sociedade a partir da escola", a escola como está configurada no nosso país, é atravessada e produz relações de poder pautadas nas políticas educacionais que emanam do Estado, e acreditar que há a possibilidade de se desvincular dessas relações seria ingenuidade. Mas, ainda em Louro (1997, p. 86) "isso implica adotar uma atitude vigilante e contínua no sentido de procurar desestabilizar as divisões e problematizar a conformidade com o "natural"; isso implica disposição e capacidade para interferir nos jogos de poder”.

Interferir nos jogos de poder não é uma tarefa fácil. A imagem do professor passa por um processo problemático de produção de sentido, o desrespeito e a retaliação são reais. Por isso Louro (1997) nos fala sobre a atitude vigilante e ativa. Embora a escola não salve a sociedade, ela pode tornar-se lugar de resistência, de lutas e conquistas, vide os movimentos de ocupações em 2016 de estudantes contrários à reforma do ensino médio.

De acordo com Louro (1997, p. 86) cabe pensarmos na escola como "prática política, isto é, que se transforma e pode ser subvertida”. Quanto mais a pesquisa na área de estudos de gênero e sexualidades se multiplicar maior serão as possibilidades de criar debate, repensar currículos, repensar pedagogias, refletir, problematizar e desconstruir verdades. 


\section{Referências}

BUTLER, J. Problemas de gênero: Feminismo e subversão da identidade. Trad. Sob a direção de Renato Aguiar. 11. ed. Rio de Janeiro: Civilização Brasileira, 2016.

DELEUZE, G. GUATARRI, F.; Mil Platôs: capitalismo e esquizofrenia 2. Trad. Sob a direção de Ana Lúcia de Oliveira, Aurélio Guerra Neto e Célia Pinto Costa. 2 ed. São Paulo: Editora 34, 2011.

SALIH, S. Judith Butler e a teoria queer. Trad. Sob a direção de Guacira Lopes Louro. Belo Horizonte: Autêntica Editora, 2015.

FISHER, R. M. B. Foucault e a análise do discurso em educação. Cad. Pesqui. [online]. 2001, n.114, pp.197-223. ISSN 0100-1574. Disponível em: http://dx.doi.org/10.1590/S010015742001000300009. Acesso em: 01 out. 2018.

FOUCAULT, M. A ordem do discurso. Aula inaugural no College d'e France, proninciada em 2 de dezembro de 1970. Trad sob a direção de Laura Fraga de Almeida Sampaio. São Paulo: Edições Loyola, 1996.

LOPES, A. C. MACEDO, E. Currículo: debates contemporâneos. São Paulo: Cortez, 2002.

LOURO, G. L. Gênero Sexualidade e Educação: Uma perspectiva pós-estruturalista. Rio de Janeiro: Vozes, 1997.

SILVA, T. T. Identidade e diferença: a perspectiva dos estudos culturais/Tomaz Tadeu da Silva (org). Stuart Hall, Kathryn Woodward. Trad. Sob a direção de Tomaz Tadeu da Slva. Rio de Janeiro: Editora Vozes, 2014.

Horizonte: Autêntica, 2007.

Identidade: uma introdução às teorias do currículo. 2 ed. Belo

EL PAÍS Brasil. Disponível em: https://brasil.elpais.com/brasil/2016/06/23/politica/1466654550_367696.html. Acesso em: 05 dez. 2018.

Revista EXAME. Disponível em: https://exame.abril.com.br/brasil/brasil-tem-5-5-milhoesde-criancas-sem-pai-no-registro/. Acesso em: 20 dez. 2018.

Portal de notícias G1. Disponível em: https://g1.globo.com/ciencia-e-saude/noticia/maioriados-casos-de-violencia-sexual-contra-criancas-e-adolescentes-ocorre-em-casa-notificacaoaumentou-83.ghtml. Acesso em: 29 jan. 2019.

Disponível em: https://g1.globo.com/economia/noticia/em-10-anosbrasil-ganha-mais-de-1-milhao-de-familias-formadas-por-maes-solteiras.ghtml. Acesso em: 20 jan. 2019. 